\title{
Treatment and Destruction of Inorganic Fibers Wastes Like Asbestos by Sodium Polyphosphate
}

\author{
P. VAST ${ }^{\star, 1,3}$, V. ANDRIÈS ${ }^{1}$, M.A.U. MARTINES ${ }^{1}$, J.P. AUFFREDIC ${ }^{2}$ M. POULAIN ${ }^{2}$, \\ Y.MESSADDEQ ${ }^{1}$ \\ ${ }^{1}$ Instituto de Quimica UNESP, Araraquara S.P. Brasil \\ ${ }^{2}$ University of Rennes1, France \\ ${ }^{3}$ Last adress Laboratoire de Chimie Appliquée, Ũniversité de Lille, France \\ * Corresponding author, 53 rue Pasteur 59810 Lesquin, France, pierre.vast@wanadoo.fr
}

\begin{abstract}
The removal and destruction of ceramic fibers wastes are presently an important problem for the society health. Among these, the asbestos, which are silicates, is the more dangerous. Usually their destruction is obtained by a melting way, but this needs high temperature (about 1500 $1600^{\circ} \mathrm{C}$ ) and presents an expensive treatment. In this paper we show that the sodium polyphosphate addition to different asbestos (chrysotile, amosite and crocidolite) permits to obtain the fiber's destruction at a temperature below than $900^{\circ} \mathrm{C}$. This process may be applied to composite materials containing a few part of asbestos, like carpet tiles or building plaster. This process of waste's treatment can open a new and a large market for sodium polyphosphate.
\end{abstract}

\section{INTRODUCTION}

Phosphate compounds are extensively used in industry and human environment areas. Typical examples relate to fertilizers, animal - and also human -food, pharmacology and cosmetics. These applications consume a significant tonnage of the world phosphate production. In addition, the non-biological industrial applications also require large amounts of phosphates. For example, they are used in many areas like metal surface treatment, enameling, ceramics processing, flame retardant, washing powder, optical glasses, water treatment, paints, filler for plastics and papers, etc.

Nevertheless, the use of phosphate processing for waste treatment - particularly inorganic wastes - appears presently as a minor application for the phosphate productions. While some applications have been proposed in this area, especially for the treatment of nuclear wastes ${ }^{1,2,3}$, these applications are rather a matter of basic researches without industrial counterparts. On the other hand, this kind of application does not require an important quantity of phosphates and derivatives.

We propose here to use phosphate compounds, in particular polyphosphates, for the treatment of inorganic wastes, which could open a new and large market for these products.

Because the polyphosphate solutions exhibit interesting properties like their colloid disperse power and their important wetting power on inorganic ceramic (or metal) particles. On heating, polyphosphates may react with these particles, in particular through oxoacidity reaction ${ }^{4}$. Finally, sodium polyphosphate which is commercially sold as Graham salts or as hexametaphosphate is an important and cheap industrial product. 
Among the inorganic wastes, an important world problem concerns the destroying (or the neutralization) of the inorganic fiber wastes.

In this respect, asbestos presents a major concern which raises problems for the human health in many countries, because very large amounts were used during the last century, at once in industrial and domestic applications. Asbestos have been used directly as a protection against noise or heat propagation. Because of their mechanical properties, they have also been used as filler, in variable quantities, in "composites" materials based on organic or inorganic matrix. In these last cases, one may have to destroy these fibers inside the matrix, even if the relative amount of asbestos is limited. As a consequence, the waste tonnage to be treated is enormous. This outlines the economic importance of the treatment of asbestos which is often a mere filler in organic or inorganic matrix.

\section{The reasons of the asbestos hazards}

The asbestos are silicate compounds. About mineralogy they may classified in two categories ${ }^{5}$. The serpentines with the chrysotile as the principal fiber (white asbestos) are the most used in human applications.

The general formula is $\mathrm{Mg}_{3} \mathrm{Si}_{2} \mathrm{O}_{5}(\mathrm{OH})_{4}$, with sometimes iron traces. They have a layered structure, but these silicates layers are coiled up in a principal direction, which results in a linear structure with an outside diameter about of $25 \mathrm{~nm}^{6}$.

The amphiboles make the second category. The main fibers are:

- The crocidolite $\left(\mathrm{Na}_{2} \mathrm{Fe}_{5} \mathrm{SiO}_{22}(\mathrm{OH})_{2}\right)$-(blue asbestos)

- The amosite $\left(\mathrm{Mg}_{2} \mathrm{Fe}_{5} \mathrm{SiO}_{22}(\mathrm{OH})_{2}\right)$ - (brown asbestos)

- The tremolite $\left(\mathrm{Ca}_{2} \mathrm{Mg}_{5} \mathrm{SiO}_{22}(\mathrm{OH})_{2}\right)$

All amphibole structures are linear at the molecule size.

So in natural site asbestos are not much toxic, but their mechanical treatments carry especially the breaks along the fiber direction and not across.

For this reason during the elaboration of materials based on asbestos, the fibers become thinner and thinner. As they become more and more dangerous for the human respiratory system. In practice, it is acknowledged that the most dangerous fibers have approximately a length of 5 microns and a diameter of 3 microns.

On the other hand, amphiboles dangerousness is not only due to the crystallographic structure, but also to the chemical toxicity induced by iron II presence.

There is a major interest to cut by a chemical reaction the linear molecular structure of the asbestos because it is a way to destroy their hazards. But this reaction has to be obtained with an inexpensive process for economic reasons, and should not produce other hazardous wastes. The elimination of iron II is also a goal for the treatment of amphiboles.

\section{The use of sodium polyphosphate for the treatment of asbestos}

Commercial sodium polyphosphates are glasses. They have a chain structure with different chain length ${ }^{7}$. Usually in the commercial product the value of the chain length lies between 10 and 25 units of $\mathrm{PO}_{3}{ }^{8}$.

It is the only polyphosphate which is soluble in water ${ }^{7}$. In this case, it gives an acid solution.

The wetting power of aqueous polyphosphate solution to the asbestos fibers is very interesting. For example the figure 1 shows the evolution versus time, of the wet part of a chrysotile tuft soaked partly above a $4 \mathrm{M}$ sodium polyphosphate solution ${ }^{9}$. This result 
exemplifies the interest of polyphosphate for the impregnation of asbestos items of important thickness such as the flock coating on building ceiling ${ }^{16}$. This good wettability permits to impregnate to tuft core as shown in figure 2 which reports a TEM analysis.

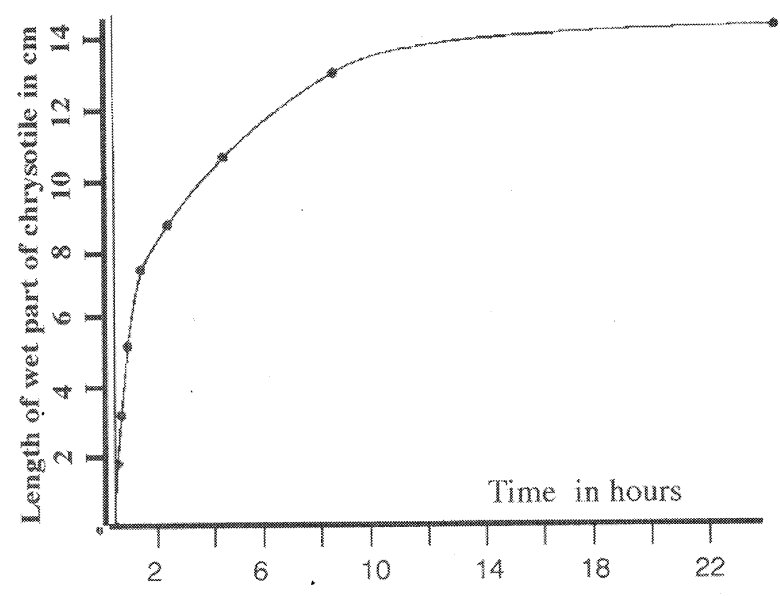

Figure 1: Wettability of chrysotile tuft by a sodium polyphosphate solution at room temperature

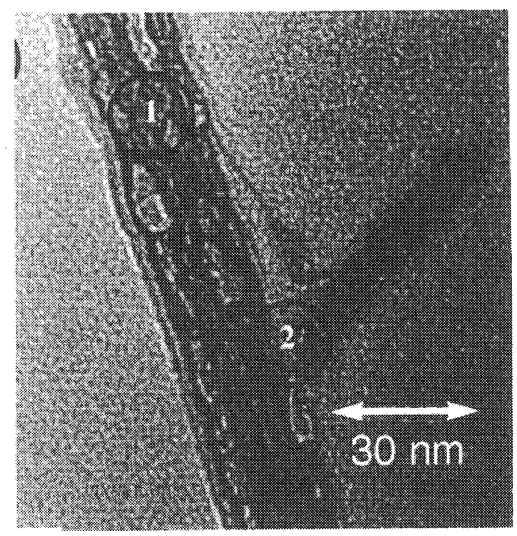

Figure 2: TEM analysis of a fiber coming from a chrysotile tuft treated by sodium polyphosphate solution. In the areas 1 and 2 present respectively 4 and $5 \%$ of phosphorus element around the elementary fiber

Another property may be used for the asbestos treatment9. Sodium polyphosphate aqueous solution gives a miscibility gap phenomenon by adding bivalent ions ${ }^{8,9,10,11}$. In this way we obtain a segregation of the long chains of polyphosphate, which conducts to a new phase called coacervate ${ }^{12}$. The $\mathrm{pH}$ of the mixture decreases during the coacervate formation down to 2 or $3^{13}$. For this reason the coacervate formation is favored if asbestos are mixed with another salts containing bivalent ions. This behavior opens new possibilities because 
coacervates present interesting rheologic properties 14 . They behave as a glue which prevents the departure of asbestos fibers during their mechanical removing ${ }^{15,16}$.

By curing we obtain in a first step a dehydration of coacervate in an oven drying conditions then up to $620^{\circ} \mathrm{C}$ their melting. The temperature of melting depends of the ratio of $\mathrm{M}^{++} / \mathrm{Na}^{17}$. Molten polyphosphate are very reactive with respect to many ceramics ${ }^{7}$. They also exhibit an important wetting power. Figure 3 shows as an example the thermal evolution of chrysotile fibers partly coated by a dried coacervate. This study implemented by SEM shows that fibers which were not completely coated in the first stage of the melting became wholly covered.

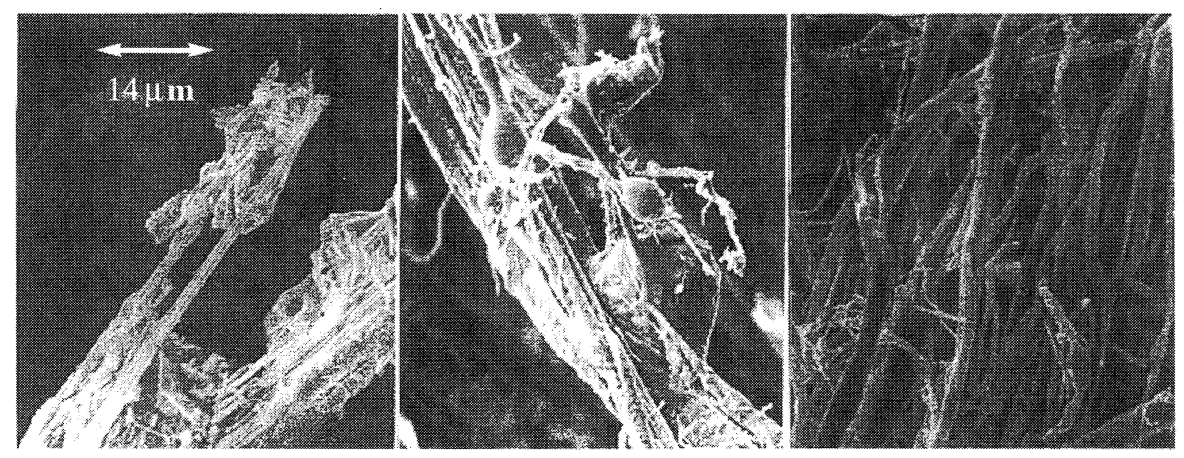

Figure 3: SEM views of the wettability evolution of chrysotile fibers by polyphosphate glasses as the increasing temperature around the melting point of sodium polyphosphate. From left to right, we can see the increasing of the coating of fiber by the glasses

\section{STUDIES OF ASBESTOS DESTRUCTION BY THE SODIUM POLYPHOSPHATE}

In a first time, we have studied the destruction of three typical kinds of asbestos fibers.

Our goal was to show the possibility of sodium polyphosphate to cut the linear structure of asbestos in a low temperature range, in order to decrease the dangerousness of this kind of fibers.

\section{Experimental}

The sodium polyphosphate is a Merck product sale as Graham salts. The chain length is $22-$ 25 units of $\mathrm{PO}_{3}$ groups.

The asbestos samples are supplied by Ward's natural science establishment Rochester, New York USA.

\section{A: Chrysotile}

Thermal analysis

Sodium polyphosphate presents a classic thermal analysis curve of glasses. The Tg, $\mathrm{Td}$ and $\mathrm{Tm}$ are respectively about 260,300 , and $620^{\circ} \mathrm{C}$. Characteristic temperatures vary in accordance with their chains lengths ${ }^{7,17}$.

The thermal decomposition of chrysotile is also well known. The dehydroxylation of chrysotile takes place near $640^{\circ} \mathrm{C}$ and at $800-850^{\circ} \mathrm{C}$ the anhydride breaks down in forsterite and silica ${ }^{18}$. Forsterite is well crystallized and persists together with the silica up to $1000^{\circ} \mathrm{C}$, keeping a fiber structure. 
The figure 4 shows the DTA study of sodium polyphosphate, chrysotile and chrysotile impregnated by a solution (4M) of sodium polyphosphate. The sodium polyphosphate present a classical curve, and we can see about the chrysotile the dehydration phenomenon and the formation of forsterite. However, the chrysotile impregnated by sodium polyphosphate gives another kind of curve. At the temperature of the dehydration of the chrysotile we have a beginning of an endothermic peak and an important exothermic peak appears at the same temperature that the melting point of the sodium polyphosphate. Moreover the peak at $800-$ $850^{\circ} \mathrm{C}$ which corresponds to the forsterite, $\left(\mathrm{Mg}_{2} \mathrm{SiO}_{4}\right)$ formation disappears.

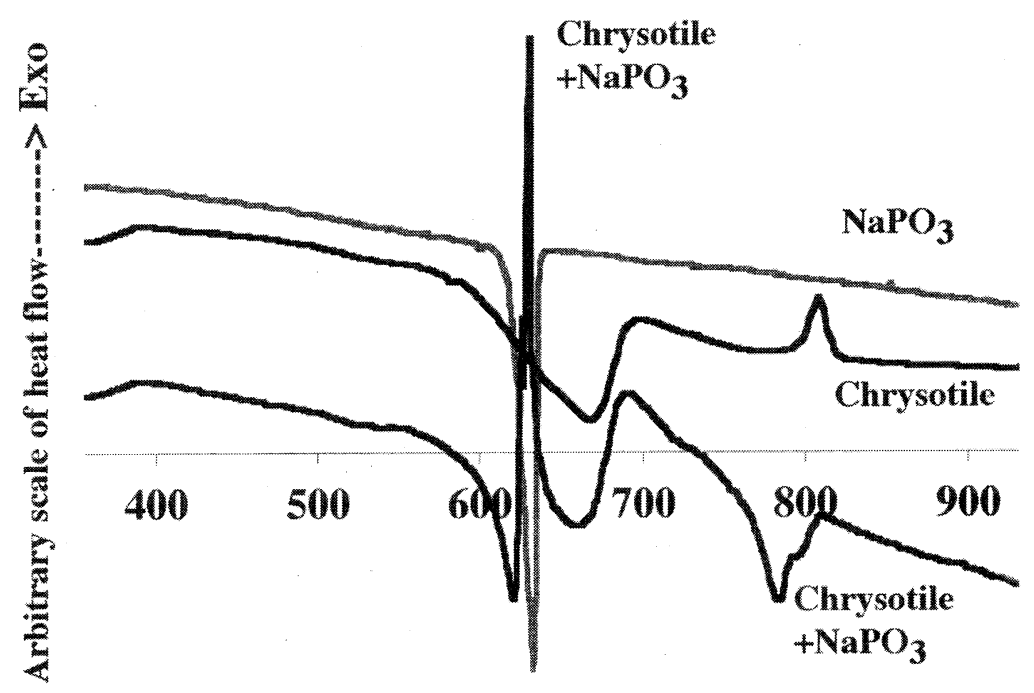

Temperature ${ }^{\circ} \mathrm{C}$

Figure 4: Comparative DTA study of sodium polyphosphate, chrysotile and a mixing of chrysotile and sodium polyphosphate

\section{Structural evolutions}

These reactions have been characterized by 29Si MAS NMR spectrum at different temperatures (Figure 5). For the chrysotile alone, we observe after curing at $1000^{\circ} \mathrm{C}$ the forsterite formation. But from chrysotile impregnated by sodium polyphosphate we obtain silica after the momentary formation of chrystobalite.

This result confirms the destruction of the molecular structure of the chrysotile.

The $\mathrm{X}$ rays analysis, confirms these evolutions of chrysotile (Figure 6). For the chrysotile alone we obtain no important change of the spectra up to the dehydration reaction. After that we can see the formation of forsterite and a few quantity of enstatite $\left(\mathrm{Mg} \mathrm{SiO}_{3}\right)$. In presence of sodium polyphosphate, we obtain a different Xray spectrum at a temperature upper than the dehydration of chrysotile temperature (Figure 6). In particular, we detect the formation of crystobalite above $800^{\circ} \mathrm{C}$. 


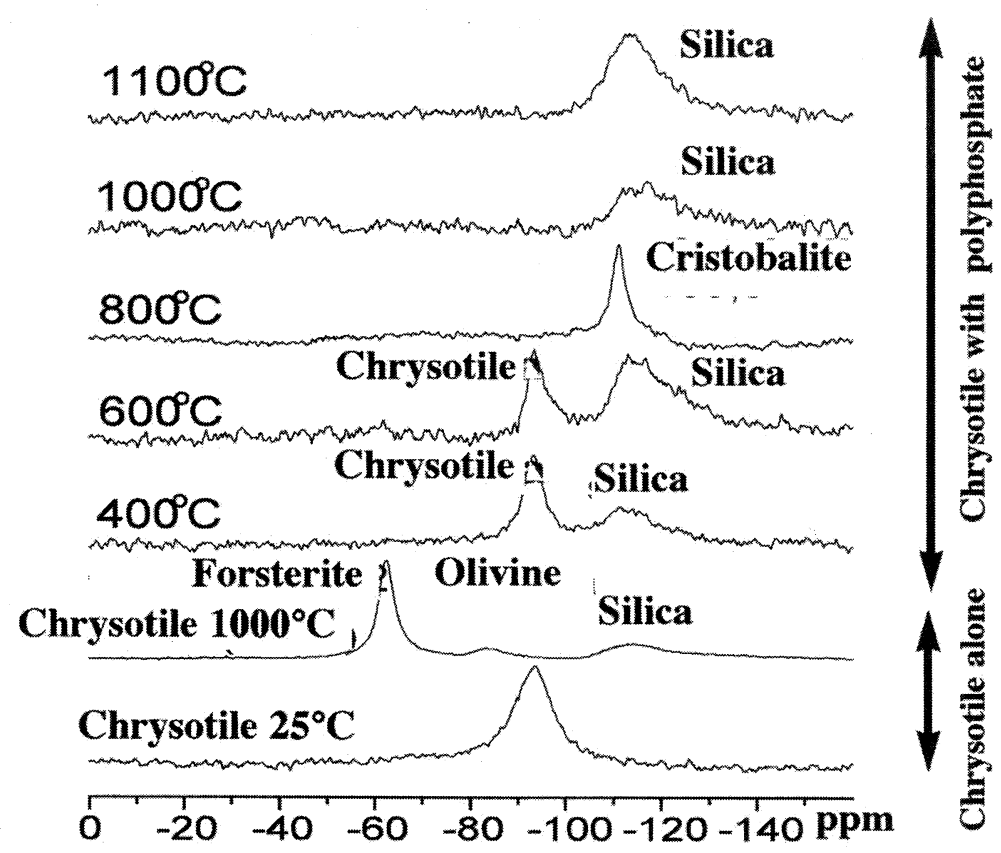

Figure 5: MAS NMR of ${ }^{29} \mathrm{Si}$, top: The evolution of spectra with temperature for chrysotile with sodium polyphosphate, down: Chrysotile alone at low and high temperature
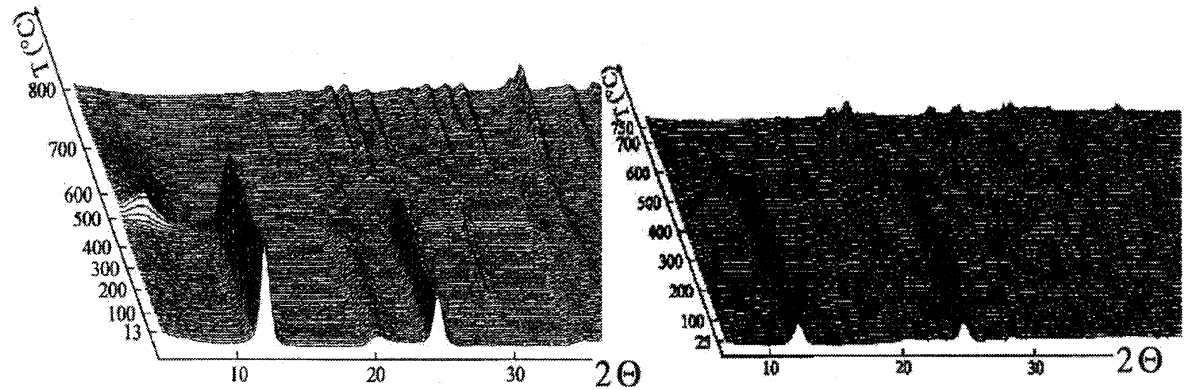

Figure 6: X Ray diffraction patterns versus temperature in nitrogen atmosphere of chrysotile alone (left) or chrysotile with sodium polyphosphate (right)-Siemens generator with INEL detector (anticathode in copper) 


\section{Microscopy study}

By SEM we confirm thedestruction of fiber structure of chrysotile (Figure 7). The microanalysis shows the presence of phosphorus inside of the residual matter (Figure 7).
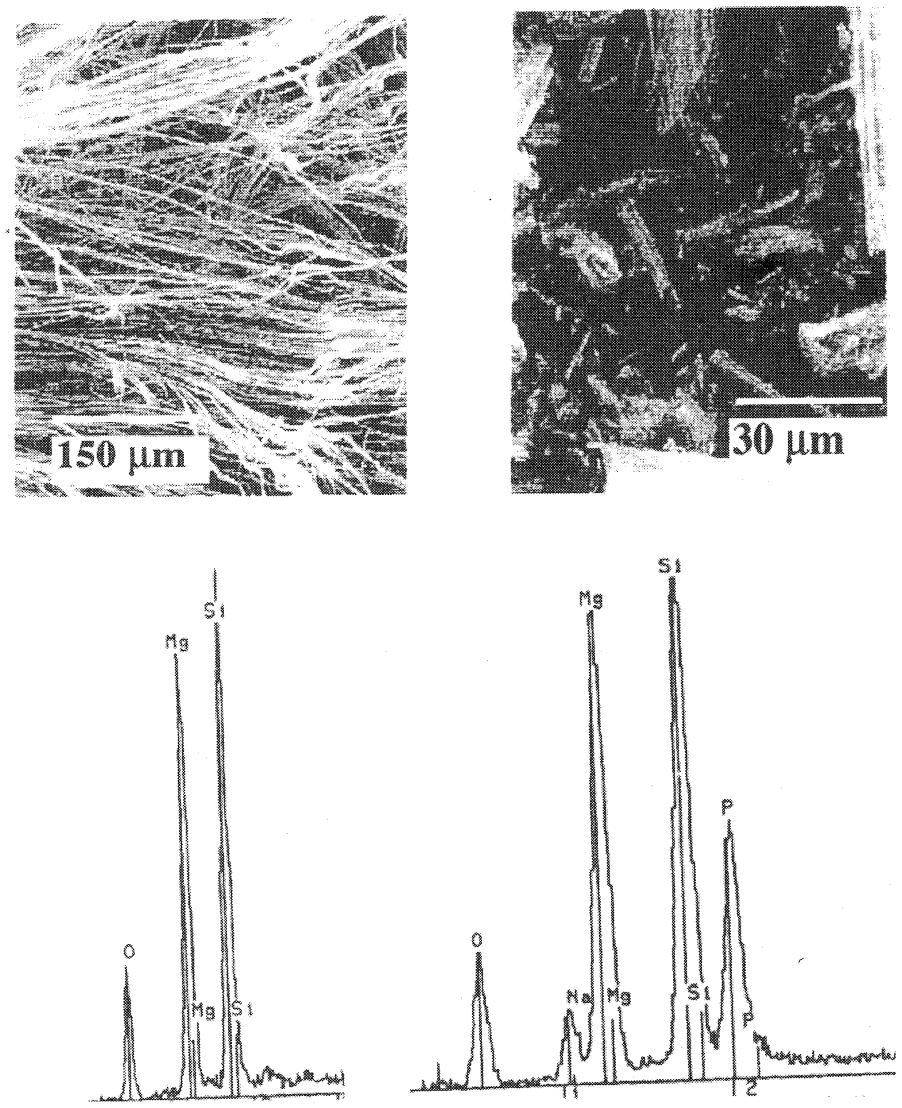

Figure 7: SEM and microanalysis of chrysotile alone (left) and chrysatile cured with sodium polyphosphate at $800^{\circ} \mathrm{C}$ (right)

\section{B: Amosite}

\section{Thermal analysis}

The Figure 8 shows the DTA curves of amosite, sodium polyphosphate and amosite treated by sodium polyphosphate. On amosite DTA curve we observe no important evolution. Sodium polyphosphate DTA curves present a melting peak at $620^{\circ} \mathrm{C}$. For the mixture, we observe an exothermic peak after melting, such as for the chrysotile. Moreover, the melting peak area of the mixture is lower than melting peak area of the polyphosphate. This result is in according with a reaction at the temperature of the melting of sodium polyphosphate. 


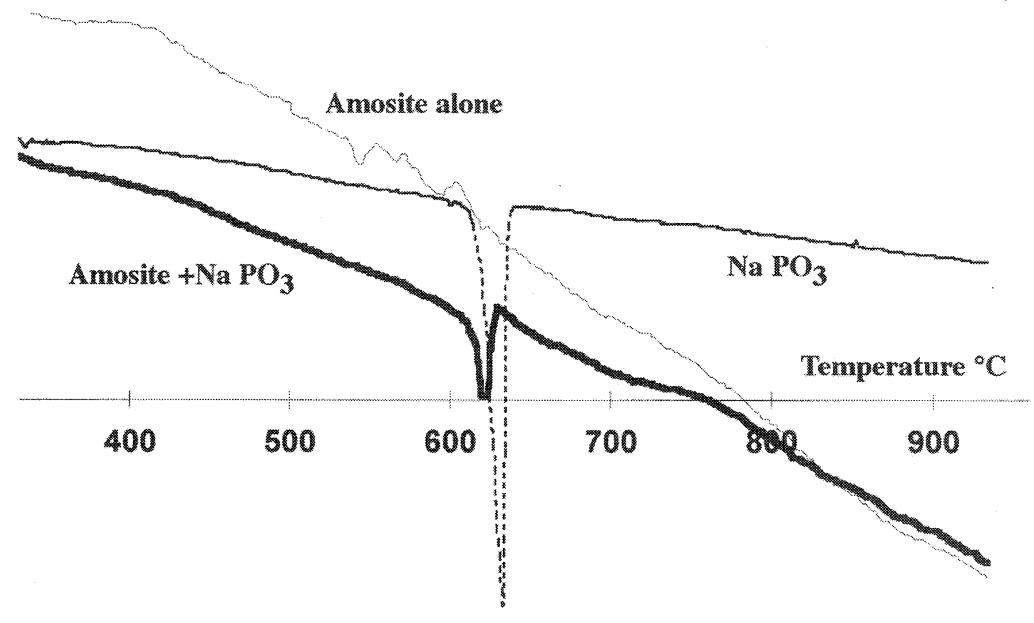

Figure 8: Comparative DTA study of sodium polyphosphate, amosite and a mixing of amosite with sodium polyphosphate

\section{Structural evolutions}

$\mathrm{X}$ rays analysis, in function with temperature, confirms this hypothesis. Figure 9 shows the evolution of the spectra. For amosite alone, we have no evolution with temperature. In other hand, in presence of sodium polyphosphate, the observe two phenomenon, in first the disappearance of the more important rays of amosite at the melting temperature of sodium polyphosphate, in second some evolution for the X rays spectra at lower temperature.
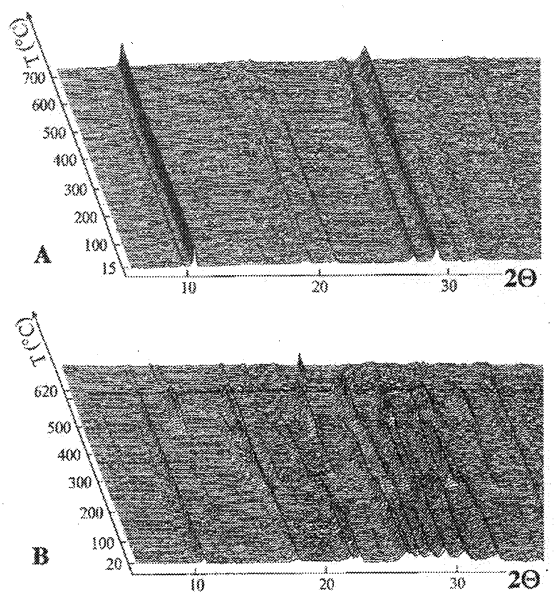

Figure 9: X Ray diffraction patterns versus temperature in nitrogen atmosphere of amosite alone

(A) and amosite with sodium polyphosphate (B)

Siemens generator with INEL detector (anticathode in copper)

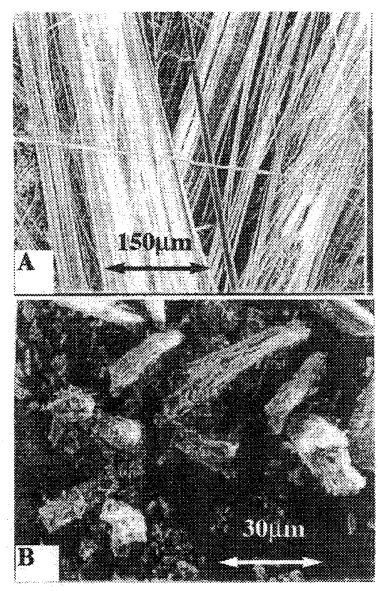

Figure 10: SEM views of amosite alone (A) and amosite cured with sodium polyphosphate at $800^{\circ} \mathrm{C}(\mathrm{B})$ 


\section{Microscopy study}

SEM study shows as for chrysotile, the destruction of the fiber structure of amosite after curing with sodium polyphosphate at $850^{\circ} \mathrm{C}$, such as for chrysotile - figure 10.

\section{C: Crocidolite}

We have begun to study the destruction of this kind of asbestos. The first very interesting information concerns the influenc of sodium polyphosphate the iron II of the crocidolite. By Mösbouer spectroscopy, we have show that the iron II is extracted by the solution of sodium polyphosphate ${ }^{20,21}$.

By $X$ rays analysis, in function with temperature we observe a complex evolution of the crocidolite structure, in comparison with the behavior of the crocidolite alone (Figure 11). The fiber structure appears also to be destroyed by the treatment with sodium polyphosphate. An optical microscopy study confirms this result (Figure 12).

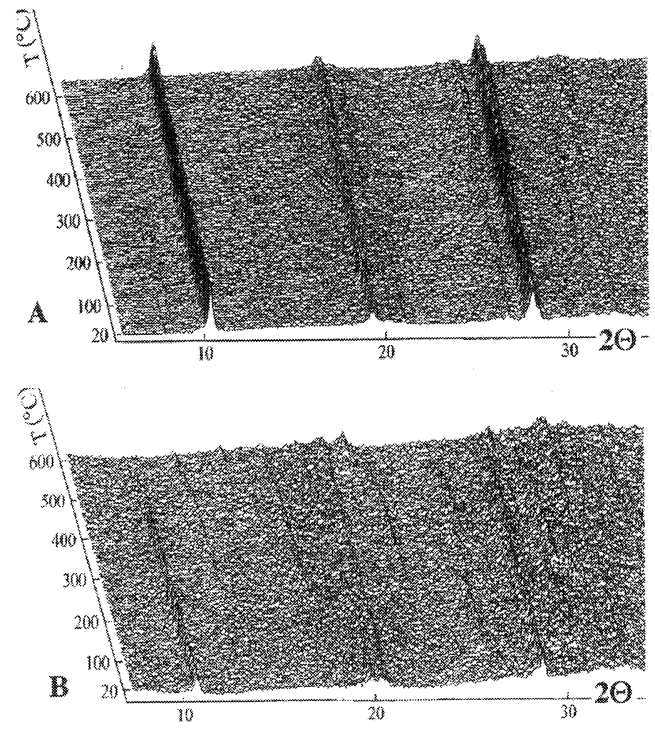

Figure 11: X Ray diffraction patterns versus temperature in nitrogen atmosphere of crocidolite alone $(A)$ and crocidolite with sodium polyphosphate (B)
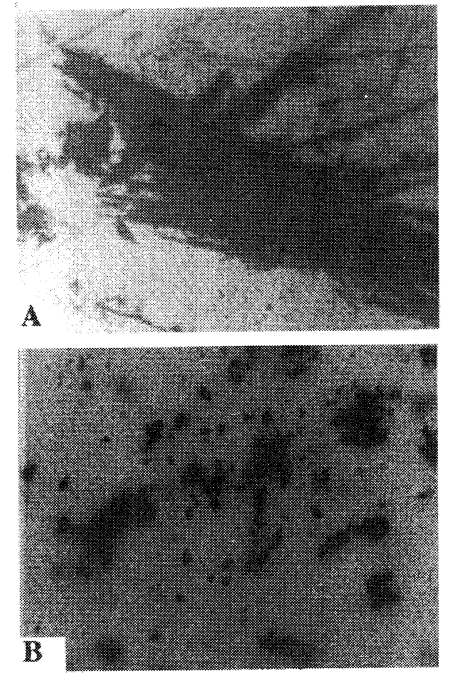

Figure 12: Optical microscopy views (x50) of crocidolite alone (A) and crocidolite cured with sodium polyphosphate at $800^{\circ} \mathrm{C}(\mathrm{B})$

In conclusion we can see that the linear structure of different kinds of asbestos may be destroyed at a temperature near the melting point of sodium polyphosphate. Nevertheless to apply this process in an industrial system we have to appreciate the cost of this treatment, by optimisation of polyphosphate quantity.

As chrysotile is the most used of all asbestos type, we have chosen chrysotile fiber to evaluate optimal quantity of polyphosphate. Thermal analysis represents a good tool to follow up destruction process, even in industrial site. 
The exothermic thermal transition chrysotile--> forsterite, at about $820-830^{\circ} \mathrm{C}$, permits to appreciate the chrysotile quantity in a sample of fibers.

Figure 13 shows the evolution of this exothermic peak from several thermograms with the same quantity of chrysotile and different mass ratio beside the sodium polyphosphate. For a ratio of a quater, we obverse an important decrease of the transition peak, and the last one disappears for a quantity of polyphosphate of a third, in mass, of sodium polyphosphate showing the destruction of chrysotile.

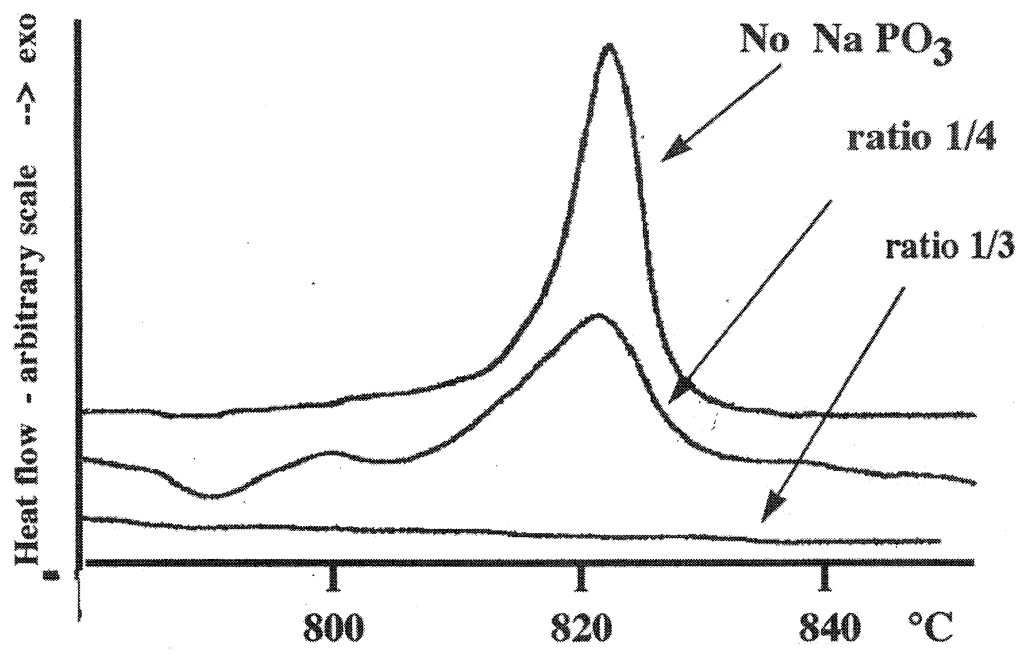

Figure 13: DTA curves evolution for different adding in mass of sodium polyphosphate to chrysotile

\section{APPLICATIONS TO MATERIALS CONTAINING ASBESTOS}

We have applied these results with two kinds of materials.

The first concerns materials which are composed essentially by asbestos, like flock coating, or asbestos cords.

For flock coating, we have showed in a previous work the interest of the sodium polyphosphate, for the removing and the destruction of asbestos fibers ${ }^{15}$.

In a same manner we have treated an asbestos cord. Figure 14 shows the evolution of a section impregnated by sodium polyphosphate before and during the curing. After the melting temperature of polyphosphate, the fibrous nature the cord is destroyed.

The second concerns materials where the asbestos, in a few quantities, has been used for their mechanical properties (hidden asbestos). We have chosen two materials:

- One with an organic matrix, the carpet tiles.

- One with an inorganic matrix, the projected plaster. 

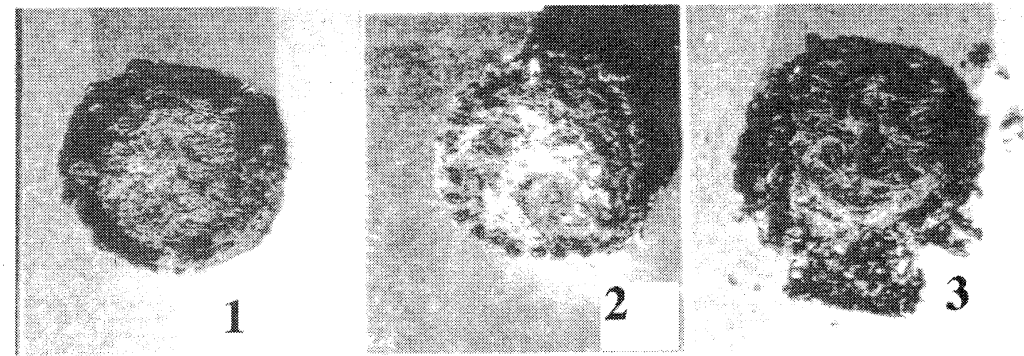

Figure 14: Evolution of a cord section; 1-cord impregnated by sodium polyphosphate; 2- the same sample cured just before the melting point of $\mathrm{NaPO}_{3}$; 3-after the melting point

\section{A: The carpet tiles}

Such composite materials as plastic carpet tiles for floor covering have been used in many quantity in the building industry ${ }^{22,23}$. To test the process based on sodium polyphosphate, we are started from samples of carpet tiles coming from pulling down wastes.

By analysis we have find polyvinyl as polymer with some benzyle, butyle and diisoundecyl phtalate as plastifier agents. For fillers, we have detected, $\mathrm{CaCO}_{3}, \mathrm{CaMg}\left(\mathrm{CO}_{3}\right)_{2}$ like dolomite, a few part of $\mathrm{SiO}_{2}, \mathrm{TiO}_{2}$, iron oxide, and of course, asbestos as chrysotile. This composition is in accordance to the bibliographical data ${ }^{23,24}$.

Of course, the polyvinyl chloride polymer matrix may be reprocessed, in spite of the chlorine control problem, in order to decrease the coast this waste treatment. Nevertheless, because of the asbestos, special treatments must be applied after removing tiles with reprocessing, or not, of the organic matter. To avoid an asbestos pollution during this treatment we have studied the behaviour of carpet tile beside the sodium polyphosphate.

We have crushed a sample of carpet tile to obtain powder in a range of $0,088-0,177 \mathrm{~mm}$ of size. By addition of a sodium polyphosphate solution of $8 \mathrm{M}$, we observe in a first time a good wettability of the grinded sample. Moreover, as the sodium polyphosphate solutions present an acidic property, the dolomite filler is destroyed and releases calcium and magnesium ions. In the presence of sodium polyphosphate, we obtain a coacervate formation. But this coacervate formation leads out also a $\mathrm{pH}$ decreasing ${ }^{13}$, which permits to increase the realize of calcium and magnesium ions, and gives more coacervate formation. As coacervates are like a glue $^{14}$, so, an industrial grinding of carpet tile in solution of sodium polyphosphate presence, permits to avoid the departure of asbestos fibers.

The curing of carpet tile impregnated by sodium polyphosphate presents two steps. The first, up to $400^{\circ} \mathrm{C}$, correspond to the degradation of the organic phase. The second, in higher temperature is due to the inorganic fillers and their potential interaction with the polyphosphates.

The figure 15 shows the DTA study of carpet tile before and after the treatment by sodium polyphosphate. For the the carpet tile alone, we can see the endothermic peak of the decomposition of carbonate and the exothermic peak which corresponds to the transition chrysotile - forsterite at $820^{\circ} \mathrm{C}$. After impregnation, we observe the decreasing of the carbonate peak and the disappearance of the transition chrysotile - forsterite. 


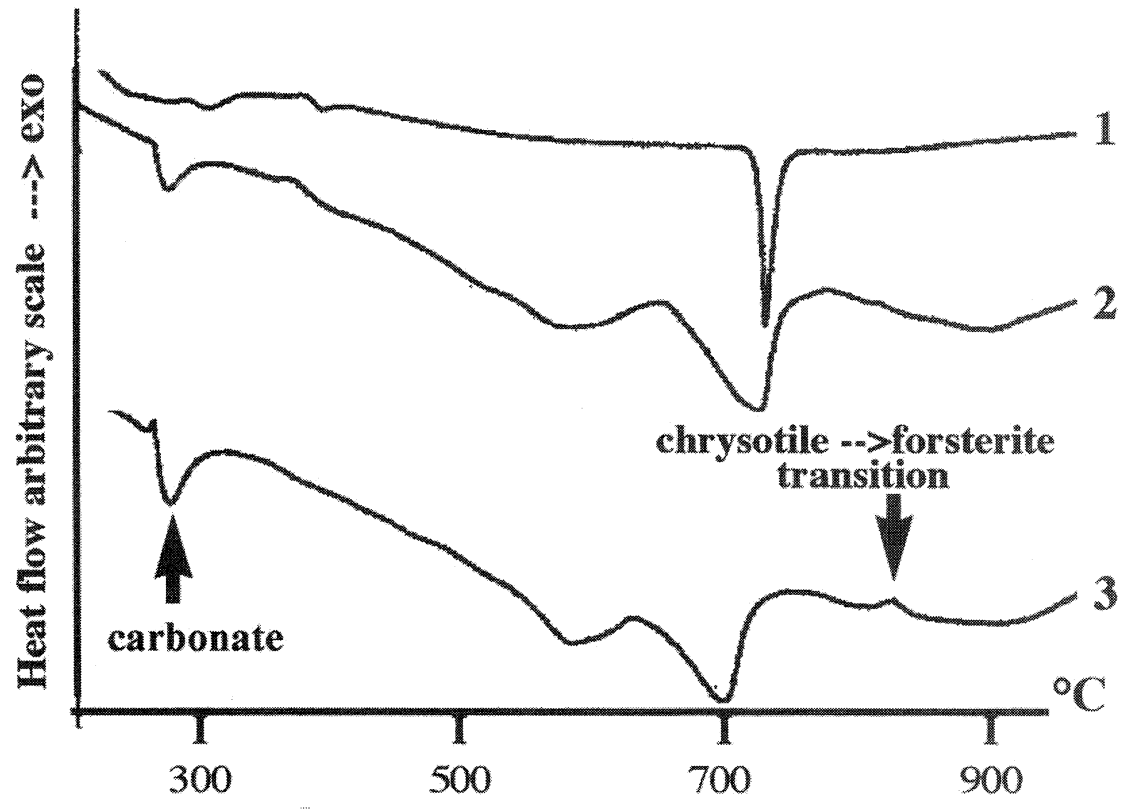

Figure 15: DTA study of $\mathrm{NaPO}_{3}$ alone (1); carpet tile alone (2); carpet tile with $\mathrm{PO}_{3}$ (3) (we can see the disappearance of the forsterite transition

The silica and rutile do not present important thermal transition in this range of temperature ${ }^{25}$. To confirm the disappearance of chrysotile, we have studied by X Rays diffraction the ashes of carpet tile alone and impregnated by sodium polyphosphate after their curing at $800^{\circ} \mathrm{C}$. For the sample treated by sodium polyphosphate, chrysotile don't appear and we obtain essentially the formation of $\mathrm{Ca} 9 \mathrm{MgNa}\left(\mathrm{PO}_{4}\right)_{7}$ crystals. For carpet tile alone, we find periclase $(\mathrm{MgO})$ coming from the initial dolomite filler.

By SEM of ashes, we can see that the chrysotile fibers are coated by a polyphosphate glass for the impregnated sample (Figure 16). The microanalysis (Figure 16) shows a presence of phosphorus in the core of fiber's tuft, which confirms the destruction of chrysotile.

\section{B: Projected plaster}

We start with samples obtained by mixing $10 \%$ of chrysotile in mass with commercial plaster and then the paste is dryed.

The plaster composite is easily wetting by a $4 \mathrm{M}$ aqueous solution of sodium polyphosphate. After drying the samples are cured up to $850^{\circ} \mathrm{C}$.

Figure 17 shows our study, for these composites, by SEM and microanalysis. We may observe:

- The plaster is impregnated in homogenous way by the sodium polyphosphate.

- The polyphosphates coat, after their melting temperature, the chrysotile fibers. Such as for the carpet tiles, phosphorus is present in the core of fiber' tuft, which is in according with the fiber's structure destruction. 

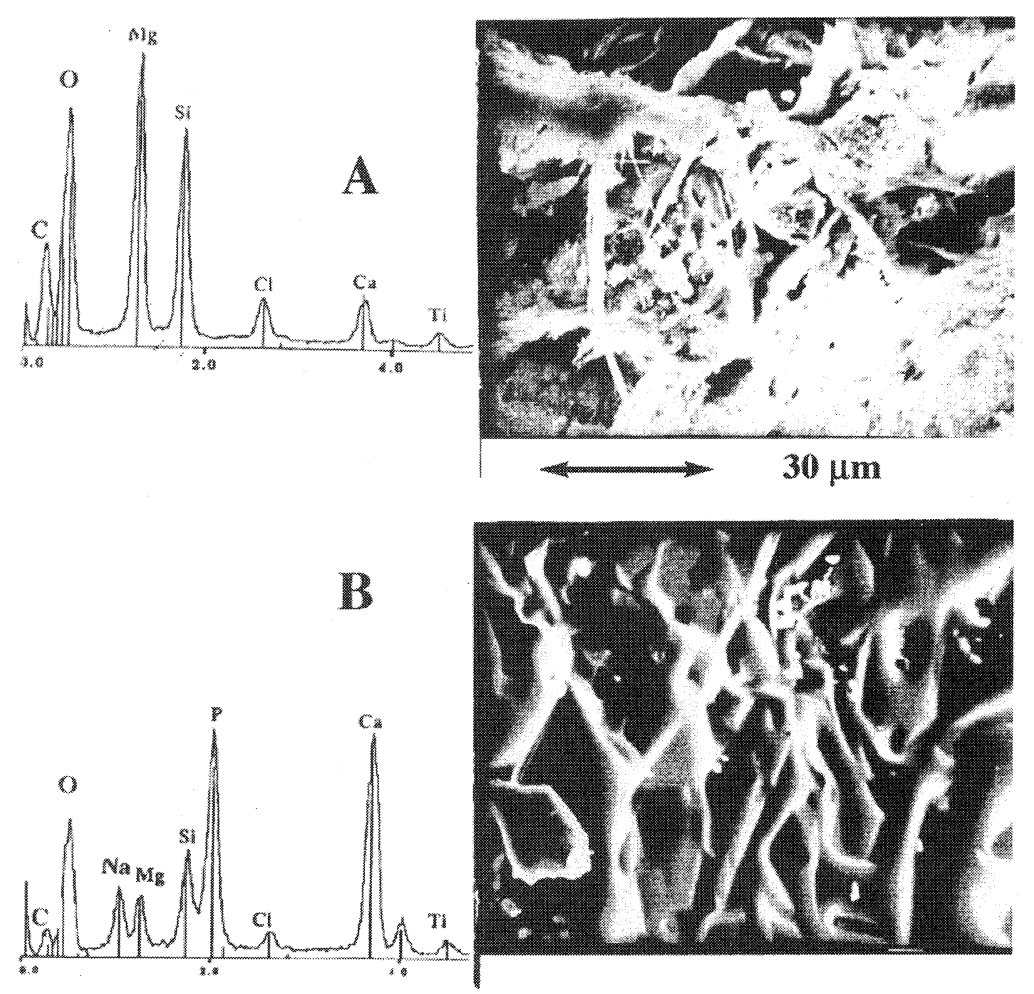

Figure 16: SEM views and microanalysis of $(A)$ ash of carpet tile heated at $450^{\circ} \mathrm{C}$ without sodium polyphosphate and (B) ash of carpet tile heated at $450^{\circ} \mathrm{C}$ with sodium polyphosphate

\section{CONCLUSION}

Sodium polyphosphate (as hexametaphosphate or Graham salts according to the commercial name) appears as an interesting product for the destruction of the asbestos fibers, at a temperature lower than $900^{\circ} \mathrm{C}$.

As the hazard of asbestos comes from their fiber structure in the molecular scale, the destruction of the silicate bridges by polyphosphate permits us the obtain the non hazardness of asbestos, and present an interesting process for their treatment.

The application to materials contening asbestos in a large, and even in a little quantity, confirms the interest of this new way for the destruction of asbestos.

On the other hand, the important quantity of waste, polluted by asbestos, in the world shows the interest of a process non expensive needed in particular a thermal treatment lower than $900^{\circ} \mathrm{C}$.

In the same way, it is conceivable to use the most part of the remnants wastes as fertilizer, because the orthophosphate presence after the reaction between asbestos and polyphosphates. 


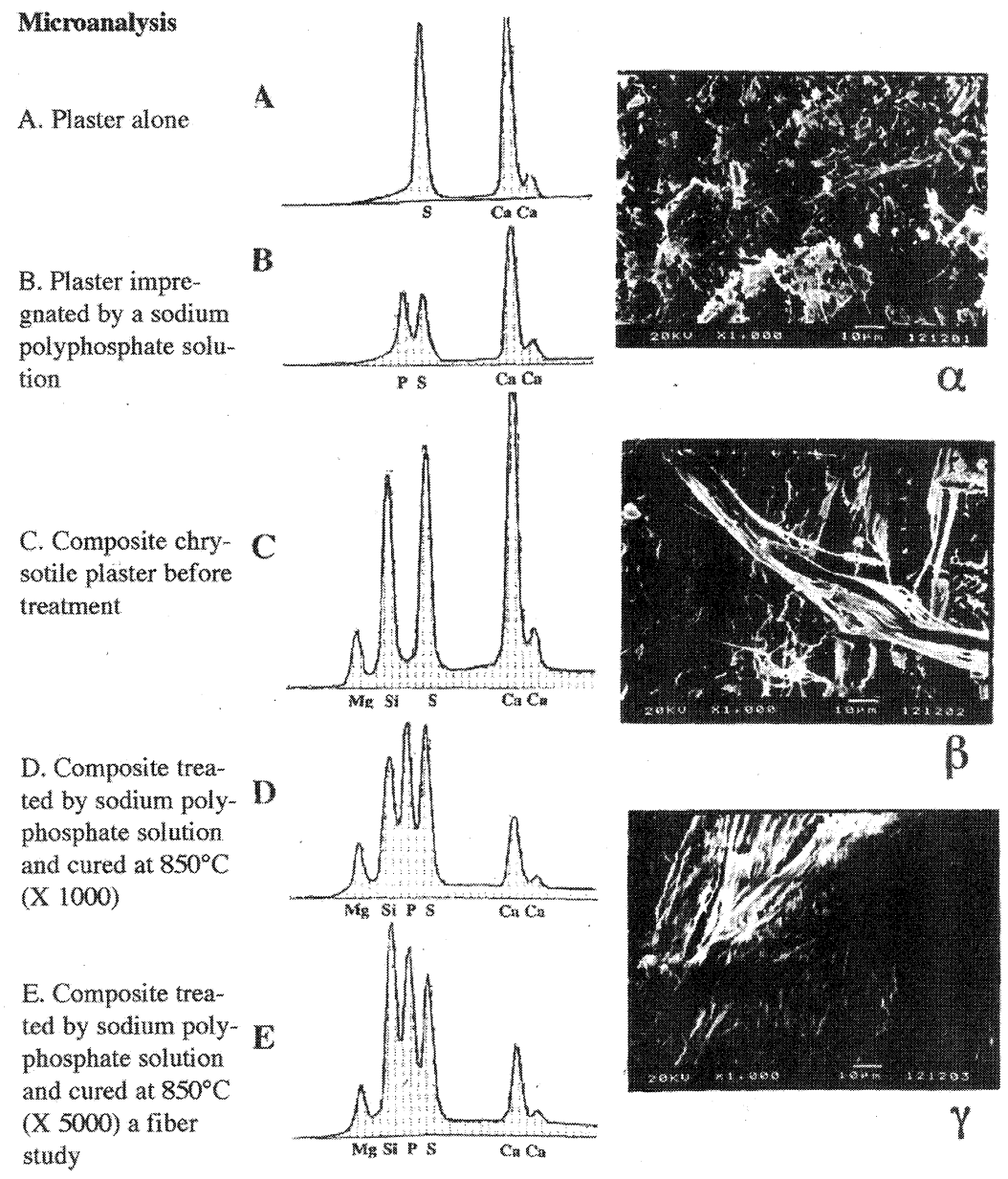

Figure 17: Composite plaster-chrysotile studied by SEM and microanalysis;

$\alpha$ initial composite; $\beta$ composite alone cured at $850^{\circ} \mathrm{C} ; \gamma$ composite treated by sodium polyphosphate and cured at $850^{\circ} \mathrm{C}$

\section{Acknowledgements}

This work has been supported partly by in France: INERTEC, in Bresil: FAPESP (Fondaçao de Amparo A Pesquisa do Estado de Sao Paulo)

\section{REFERENCES}

1. RC Ropp, in Inorganic Polymeric Glasses, Edited by Elsevier (1992)

2. M.G. Mesko, D.E. Day, J. Nuclear Materials 273, 27, (1999)

3. S.T. Reis, J.R. Martinelli, J. non Crys. Solid 247, 241, (1999)

4. L. Montagne Thesis Lille France (1991)

5. H.C.W. Skinne, R, M. Ross, J. Zussman, An introduction to the rock- forming minerals Oxford Press New York 1988 
6. S. Aemelinckx, B. Devouard, A. Baronnet, Acta Cryst A52, 850, 1996;

7. Van Wazer in Phosphorus and its compouds Voll Edited by Interscience New York 1966

8. F.Gomez, P. Vast, Phosphorus Research Bulletin, 11, 61, (2000).

9. Vast, Phosphorus Research Bulletin, 11, 69, (2000).

10. T. Kanazawa in Inorganic Phosphate Matérials Edited by Elsevier (New York 1989)

11. O. Walbrou, L. Aldon, P. Vast, D. Couturier, M.A.U Martines, J. C. Juma, Y. Messaddeq, Phosphorus Research Bulletin, 12, 211, (2001).

12. H.G. Budgenber De Jong, H.R. Kruyt, Proc. Kon. Ned. Akad. Wetensch., 32, 849, (1929).

13. F. Gomez, P. Vast, G. Willot. Phosphorus Research Bulletin, 11, 53, (2000).

14. O. Luczak, A. Ledoux, F. Gomez, P. Vast, T. Miyajima, Phosphorus Research Bulletin, 7, 23, (1997).

15. P. Vast, Proceeding 18 International Congress on Glass (environmental issues) San Francisco 1998.

16. P. Vast, Fr98/21155, Patent 1997

17. P. Vast, F. Barbieux, F. Gomez, Verre 2,3 (1996).

18. W. Smykatz-Kloss, in Differential Thermal Analysis: Application and results in mineralogy, Springer - Verlag Berlin (1074).

19. L.Michaels, S.S Shissick, in Asbestos: properties, Applications and Hazards, Hohn Wiley \& Son Chischester, (1979).

20. L. Aldon, O. Walbrou, P. Vast, D. Couturier, M.A.U. Martines, J.C. Jumas, Y. Messaddeq, Proceding Infos- ISIPM Meeting JENA (2002)

21. L. Aldon, P. Vast, an Al to be published.

22. A. Jönsson, A.M. Tillman, T. Svensson, Building and environnement 32, 245, (1997)

23. R.C Stephenson, in Encyclopedia of polymer science and Engineering, Wiley\&Sons: Chichester, 1979.

24. T. Tunbride, Europ.Plast. News 2, 10, 45, (1975)

25. B. Deffontaines, Thesis Lille France (1991) 